\title{
Personalia usw.
}

\section{Professor Emil Philippi-Stiftung.}

Die Professor Emil Philippi-Stiftung ist zur Förderung von wissenschaftlichen Arbeiten auf denjenigen Gebieten der Geologie nnd der Paläontologie errichtet worden, auf denen sich die Arbeiten des weiland Professor Dr. E. Philippi in Jena bewegt haben.

Das diesjährige Erträgnis der Stiftung im Betrage von Eintausend Mark wird hierdurch zur Bewerbung von der unterzeichneten Kommission ausgeschrieben, der die Vergebung satzungsgemäss zusteht.

Zur Bewerbung um die Unterstützung sind berechtigt: Studierende der Universität Jena und junge Gelehrte an irgend einer deutschen fíochschule. Bei im übrigen gleicbwertigen Bewerbern erhalten solche von der Universität Jena den Vorzug.

Bewerbungen um die Unterstützung sind bis zum 1. Januar 1913 an den unterzeichneten derzeitigen Dekan der Philosophischen Fakultait, Herrn Geheimen Hofrat Professor Dr. WIEN in Jena einzureichen. Beizufïgen ist ein ausführlicher Plan über den Gang und die Ziele der in Aussicht genommenen Arbeit, ferner bei Studierenden ein Zeugnis über Fleiss und Kenntnisse, ausgestellt von ihrem derzeitigen Lehrer in Geologie.

Die Verleihung der Unterstätzung erfolgt am 25. Februar, dem Todestage Emil Philippis.

Jede mit Unterstützung der Stiftung ausgeführte Arbeit muss unter dem Titel den Vermerk tragen: "Ausgeführt mit Unterstützung der Professor Emil Philippi-Stiftung". Sieben vollständige Exemplare der Arbeit sind un die Kommission abzuliefern.

\author{
M. WIEN, \\ E. Kayser, G. Linck, G. Steinmany, O. Wilckens.
}

\section{$\dagger$ Erust von Koken. $\dagger$}

Die deutsche Wissenschaft hat einen schweren Verlust erlitten durch das frühe Hinscheiden dieses ausgezeichneten Paläontologen und Geologen. Er starb nach längerem Leiden im Alter von 52 Jahren am 21. November in Tübingen, wo er seit 1895 als Lehrer und Forscher mit grösstem Erfolge tätig gewesen ist.

\section{Richtigstellung.}

W. Paulcke bemängelt in seiner geologischen Skizzierung des Unterengadins (S. 443 u. 444 dieses Bandes) meine Darstellung von Granit- und Gneisvorkommnissen an der Clïnas bei Fettan in der von TARndzzer und mir publizierten geologischen Karte des Unterengadins und gibt an, die „ganze Südflanke des Clünas bestehe nicht aus Granit und Gneis, sondern aus einer Serie von sandigen und kalkigen Bündnerschiefern". - Demgegenüber stelle ich fest, dass meine Kartierung durchaus meinen Tagebuchnotizen entspricht; einzig die spärlichen aplitischen Granite, welche die lamprophyrischen Granite randlich begleiten, sind weggelassen worden aus Mangel an Rarim. Die bezüglichen Belegstücke liegen in der mineralog.-petrograph. Sammlung der Eidg. Techn. Hochschule; auch habe ich wiederholt die fraglichen Stellen mit Studierenden besucht.

$\mathrm{Z}$ ürich, den 22. November 1912.

U. Grubenmann. 